\title{
THE RADIOGRAPHIC CHANGES IN PERTHES' DISEASE
}

\author{
J. A. O'Garra, Liverpool, England
}

From the Royal Liverpool Children's Hospital

Considering the attention that is given to disorders of the hip and considering also how long the condition now generally known as Perthes' disease has been recognised, it is surprising that its pathogenesis is still uncertain. It is true that there is some similarity to changes in the upper femoral epiphysis that may arise when there is a specific and identifiable lesion of the neck of the femur, and in the course of general disorders such as cretinism, Mongolism, reticuloses, sickle-cell anaemia, dysplasia epiphysialis multiplex and osteo-chondro-dystrophy. But in classical Perthes' disease no causative factor can be defined. The observations in this series are not new, but are recorded in the hope that they will stimulate interest which may possibly lead to a better understanding of the condition. It is fairly common, and the small number of patients now presented (rather less than half of those treated at the Royal Liverpool Children's Hospital in the period reviewed) were selected because the radiographic examinations were comprehensive and the appearances distinct (Table I).

It seems that the changes in the radio-opaque material of the femoral head may involve the whole epiphysis or mainly the anterior part only (Figs. 1 and 2). In the present series twenty cases fell into the latter, and five into the former group. It might be that this difference forms the basis for Legg's "cap" and "mushroom" types with their differing prognosis, and for the two types described some thirty years later by Fèvre as " central " and " marginal."

Group 1: "Anterior" Perthes' disease-In these patients the anterior half or two-thirds of the head of the femur is affected. A change may occur very early and can be seen in the lateral radiograph before it is detectable in the antero-posterior view (Fig. 3). Commonly the anterior segment of the head is at first abnormally dense, and this area may be clearly demarcated from the normal posterior segment (Figs. 4, 6 and 13). Soon the dense bone begins to disappear and is replaced by a translucent area initially shaped like a tongue. This spreads through the whole front of the epiphysis, leaving a peripheral rim of bone (Figs. 4, 10 and 14). Coincidently a metaphysial change, if visible, lies at this stage mainly in the anterior third of the neck of the femur (Fig. 9). This was never seen later than six months after the onset, though the necrosis of the overlying epiphysis persisted much longer. The process of apparent fragmentation and reconstruction was completed rapidly in children under eight years of age (Figs. 6 to 8), but seemed to be much slower in older children. Figure 12 is representative of the latter; one child was aged nine and the other eleven years.

Generally, reconstruction was first shown as a fine strip of new bone in the periphery of the front of the head (Figs. 5, 15 and 18), and this spread slowly forwards and inwards until the apparent defect was made good (Figs. 11, 15 and 16). It was noted that in the young child apparent flattening in the early stages, however marked it might be, did not prevent the ultimate reconstruction of a well shaped head provided treatment was prompt and adequate (Case 3; Figs. 17 to 19).

Group 2: Involvement of the whole epiphysis-Five patients were so affected and, in all, flattening and apparent fragmentation occurred early. In one patient there was also a lesion in the centre of the metaphysis (Fig. 20). Reconstruction did not appear to begin as early as in the first group; as much as a year might elapse before any change was seen, and then it took the form of a slow progressive increase in the depth of the epiphysis (Figs. 21 and 22).

vol. 41 B, No. 3, AUGUSt 1959 


\section{TREATMENT AND RESULTS}

The children in this series were treated by traction in recumbency with the exception of a boy of twelve, who walked about in a weight-relieving caliper and a patten on the other leg. The period of recumbency was seventeen to twenty-seven months. Between two and a half to three years after the onset all the children except two were free from pain, had no limp,

TABLE I

Details of Twenty-five Patients

\begin{tabular}{|c|c|c|c|c|c|c|c|c|}
\hline \multirow[b]{2}{*}{$\begin{array}{c}\text { Case } \\
\text { number }\end{array}$} & \multicolumn{4}{|c|}{ Anterior Perthes' Disease } & \multicolumn{2}{|c|}{ Whole Head } & \multicolumn{2}{|c|}{ Perthes’ Disease } \\
\hline & $\begin{array}{c}\text { Age at } \\
\text { onset } \\
\text { (years) }\end{array}$ & Sex & $\begin{array}{l}\text { Epiphysial } \\
\text { index* }\end{array}$ & Notes & $\begin{array}{c}\text { Case } \\
\text { number }\end{array}$ & $\begin{array}{c}\text { Age at } \\
\text { onset } \\
\text { (years) }\end{array}$ & Sex & $\underset{\text { index }}{\text { Epiphysial }}$ \\
\hline 1 & 4 & $\mathbf{M}$ & $46-46$ & Bilateral & 21 & $2 \frac{1}{2}$ & $\mathbf{F}$ & 33 \\
\hline 2 & 5 & F & 43 & - & 22 & 4 & $\mathbf{M}$ & 36 \\
\hline 3 & 5 & $\mathbf{M}$ & 36 & - & 23 & 4 & $\mathbf{M}$ & 25 \\
\hline 4 & 5 & $\mathbf{M}$ & 34 & - & 24 & 5 & $\mathbf{M}$ & 32 \\
\hline 5 & 5 & $\mathbf{M}$ & 37 & - & 25 & 6 & $\mathbf{M}$ & 25 \\
\hline 6 & 5 & $\mathbf{M}$ & $37-40$ & Bilateral & \multirow{15}{*}{\multicolumn{4}{|c|}{$\begin{array}{l}\text { The normal values for the } \\
\text { epiphysial index are: under } \\
7 \text { years of age, } 45-55 \\
\text { over } 7 \text { years of age, } 35-45\end{array}$}} \\
\hline 7 & 5 & $\mathbf{M}$ & 39 & - & & & & \\
\hline 8 & 5 & $\mathbf{M}$ & 37 & - & & & & \\
\hline 9 & 5 & $\mathbf{M}$ & 37 & - & & & & \\
\hline 10 & 5 & $\mathbf{M}$ & 26 & - & & & & \\
\hline 11 & 6 & $\mathbf{F}$ & 34 & - & & & & \\
\hline 12 & 6 & $F$ & 30 & - & & & & \\
\hline 13 & 6 & $\mathbf{M}$ & 34 & - & & & & \\
\hline 14 & 6 & $\mathbf{M}$ & 25 & - & & & & \\
\hline 15 & 6 & $\mathbf{M}$ & 33 & - & & & & \\
\hline 16 & 7 & $\mathbf{M}$ & 30 & - & & & & \\
\hline 17 & 7 & $\mathbf{M}$ & 28 & - & & & & \\
\hline 18 & 7 & $F$ & 40 & - & & & & \\
\hline 19 & 9 & $\mathbf{M}$ & 25 & $\begin{array}{c}\text { Gross } \\
\text { limitation of } \\
\text { movement }\end{array}$ & & & & \\
\hline 20 & 11 & $\mathbf{M}$ & 26 & $\begin{array}{c}\text { Rotation } \\
\text { limited }\end{array}$ & & & & \\
\hline
\end{tabular}

and had full mubility of the hips. The two exceptions were boys of nine and twelve. At the time of diagnosis the necrosis in both of them was anterior. One had severe limitation of abduction and rotation and an obvious limp (Case 19; Fig. 12). The other was healed three and a half years after the onset; rotation was limited and the head was severely flattened, especially anteriorly (Case 20 ). 
In the group with " anterior" disease, eighteen patients were under eight years of age at the time of diagnosis. The radiographic results show that in eleven of these the epiphysial index (Eyre-Brook 1936) was within the normal range, and in only three did the index fall below 30 . In comparison, of the five patients in whom the whole femoral head had suffered,

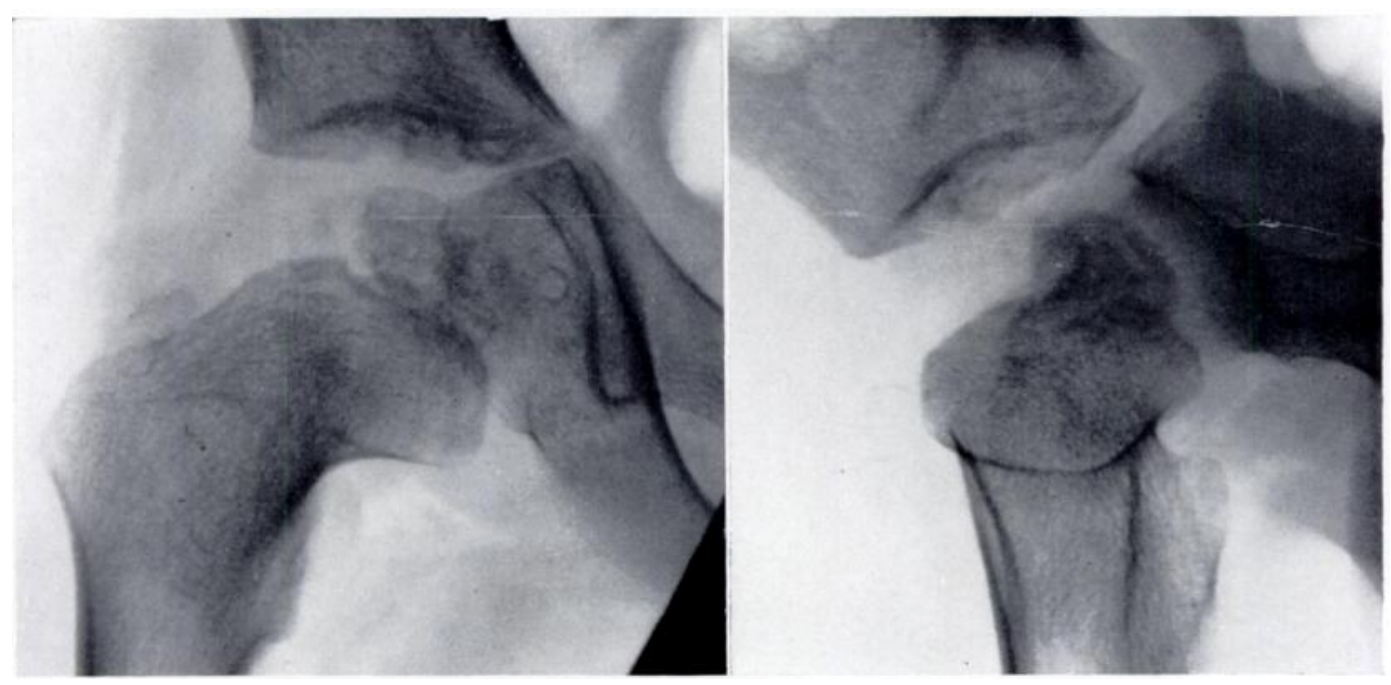

Fig. 1

Anterior Perthes' disease fourteen months after the onset. The appearance is that of a clean-cut removal of the anterior half of the femoral head, leaving a normal posterior half.

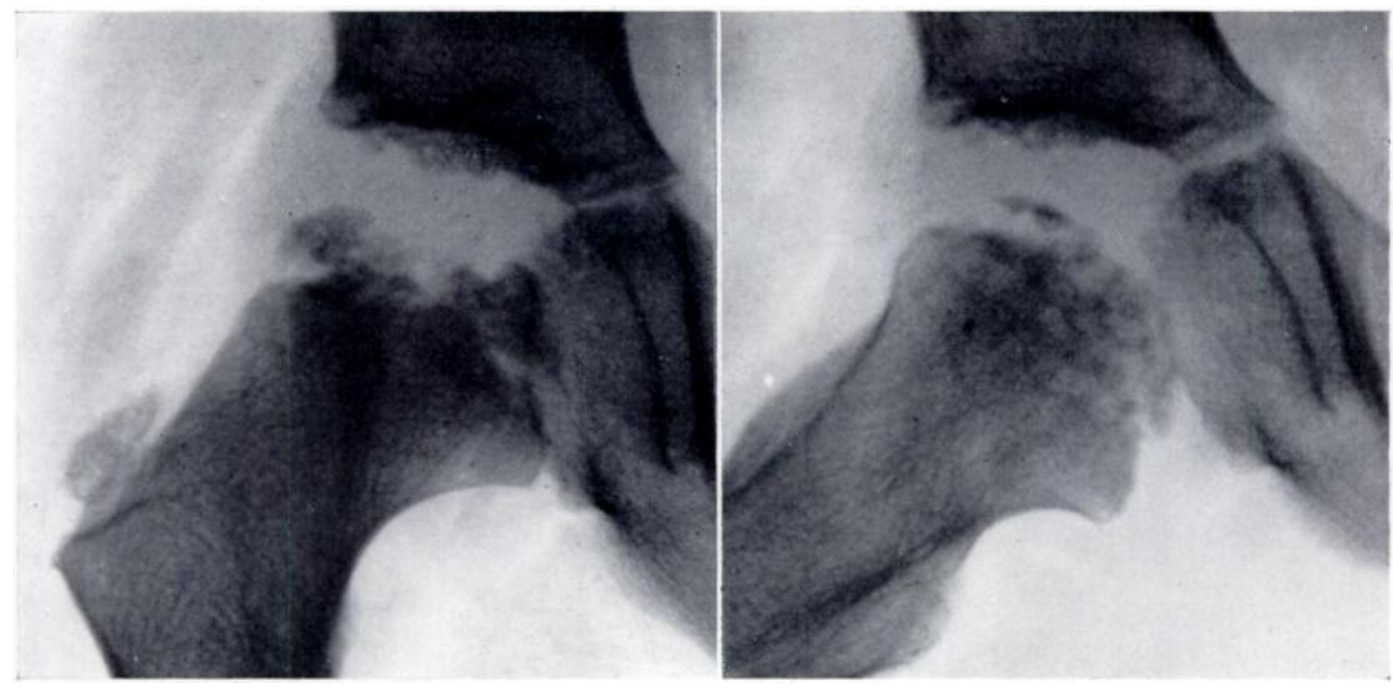

FIG. 2

Perthes' disease of the whole femoral head nine months after the first symptom. The entire epiphysis appears to be fragmented and flattened.

the epiphysial index was decidedly below normal in two, rather low in two others, and normal in only one.

\section{DISCUSSION}

Improvement in radiographic technique, including the lateral view of the hip, facilitates assessment of the lesion and observation of reconstruction. In some instances the necrosis appeared to affect only the anterior part of the capital epiphysis and was very limited; it was

VOL. 41 B, NO. 3, AUGUST 1959 

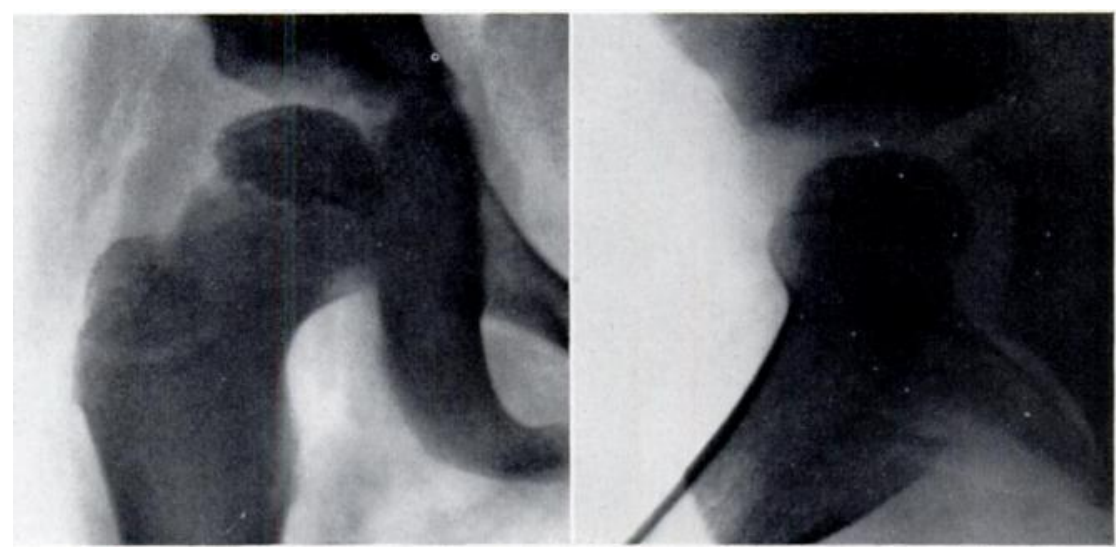

Fig. 3

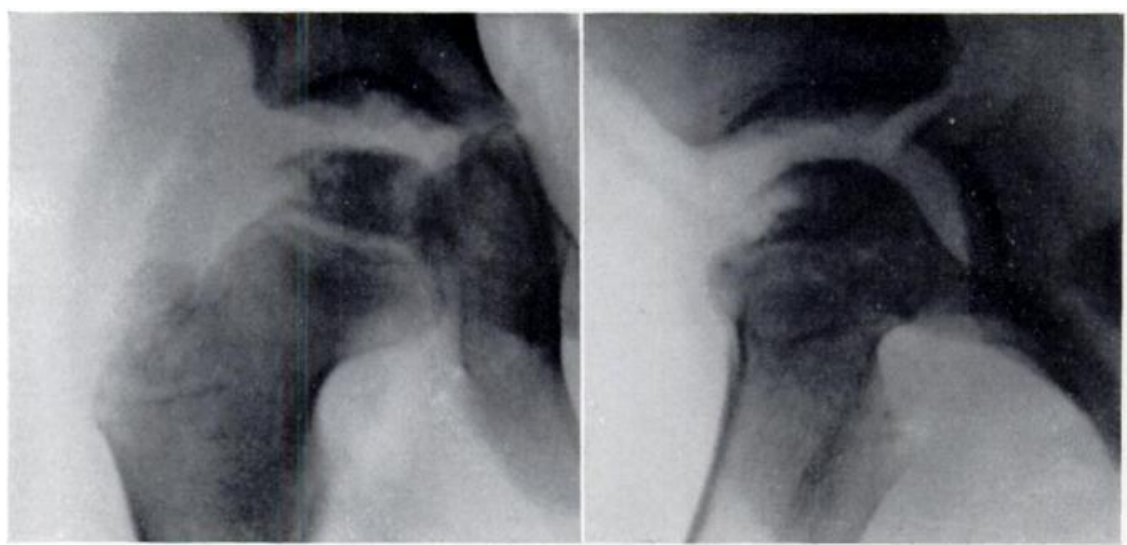

FIG. 4
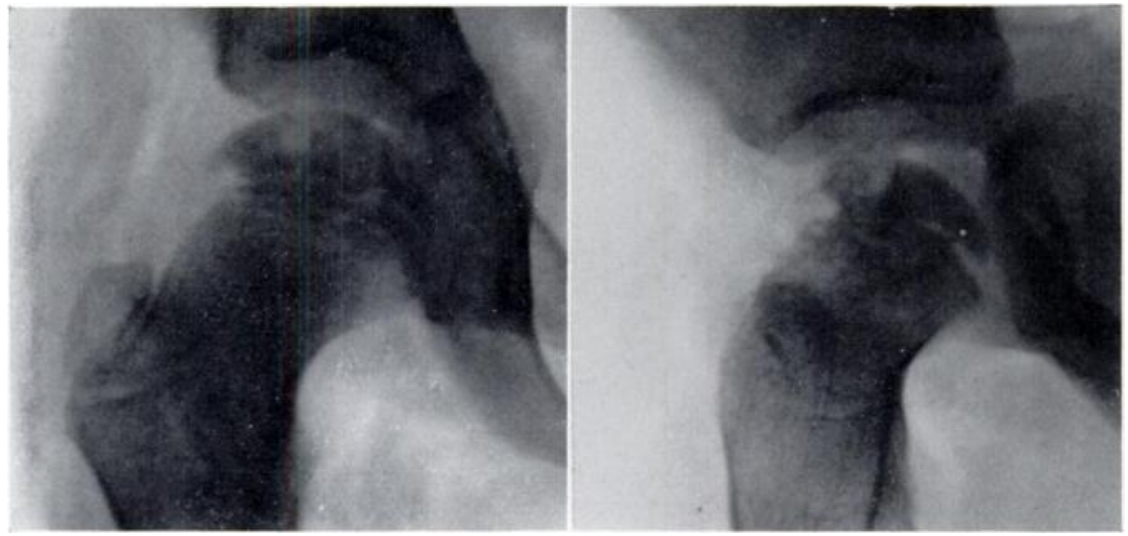

FIG. 5

Case 2. Figure 3-At commencement of treatment. Aged five years. The epiphysis is dense, has a double articular margin and shows early anterior rarefaction in the lateral projection. Figure 4-Seven months later. The stage of fragmentation. There is a tongue-shaped translucent area in the anterior segment of the femoral head. Figure 5-Five months later.

Early reconstruction. The dense bone has been almost entirely removed and new bone formation is seen in the front of the head. 

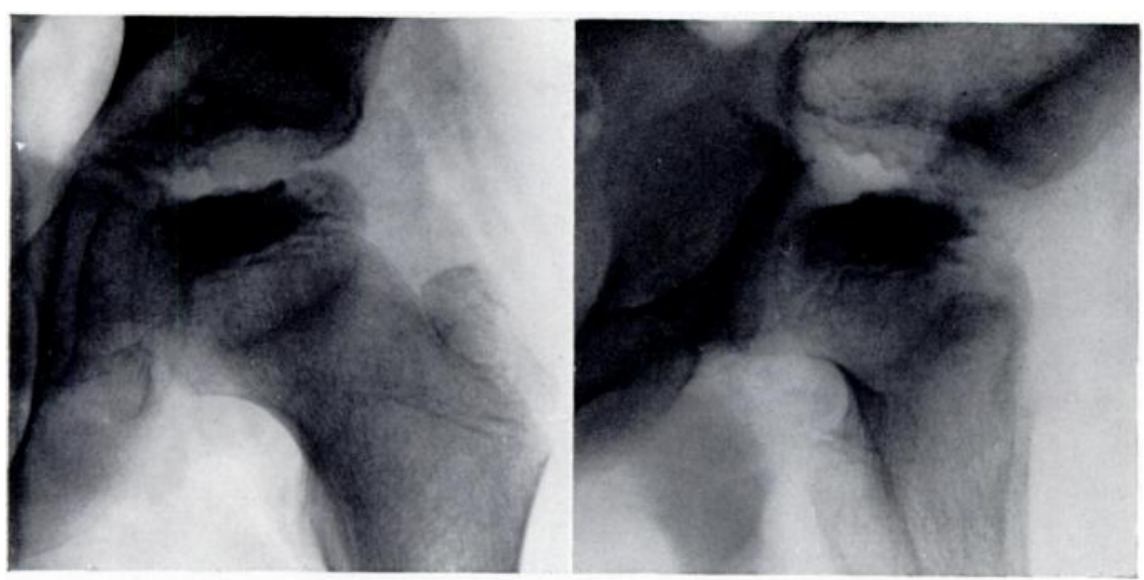

Fig. 6
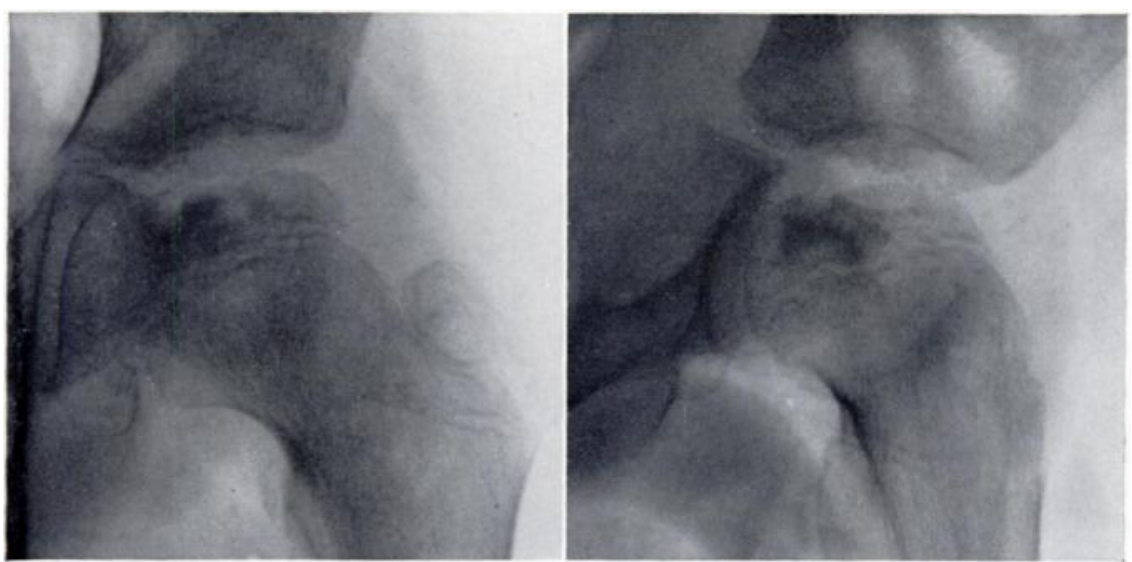

FiG. 7
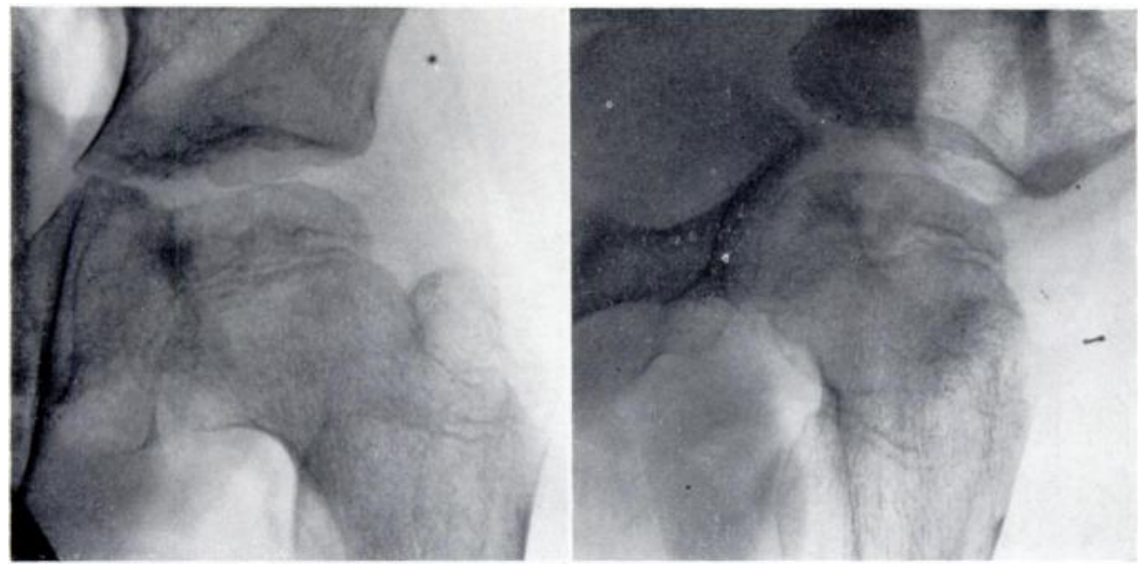

FiG. 8

Rapid reconstruction of an anterior lesion. Figure 6-Five months after the onset of symptoms. A large anterior segment of the femoral head appears abnormally dense and shrunken. Figure 7-Four months later. Most of the dense bone has been removed and replaced already by bone of normal appearance. Figure 8 -Three months later. Reconstruction is practically complete.

Vol. 41 B, NO. 3, AUGUST 1959 


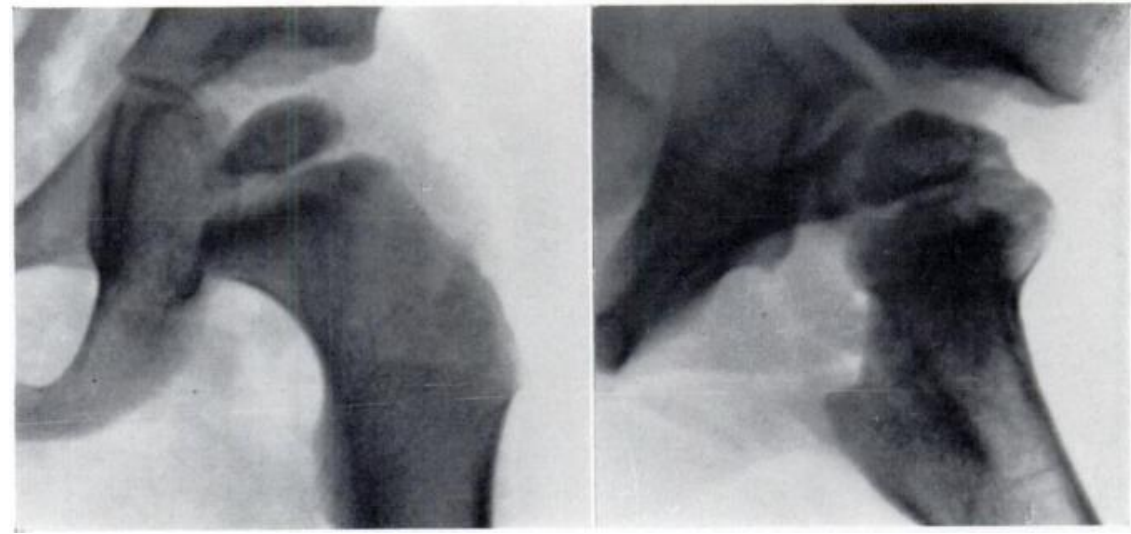

FIG. 9
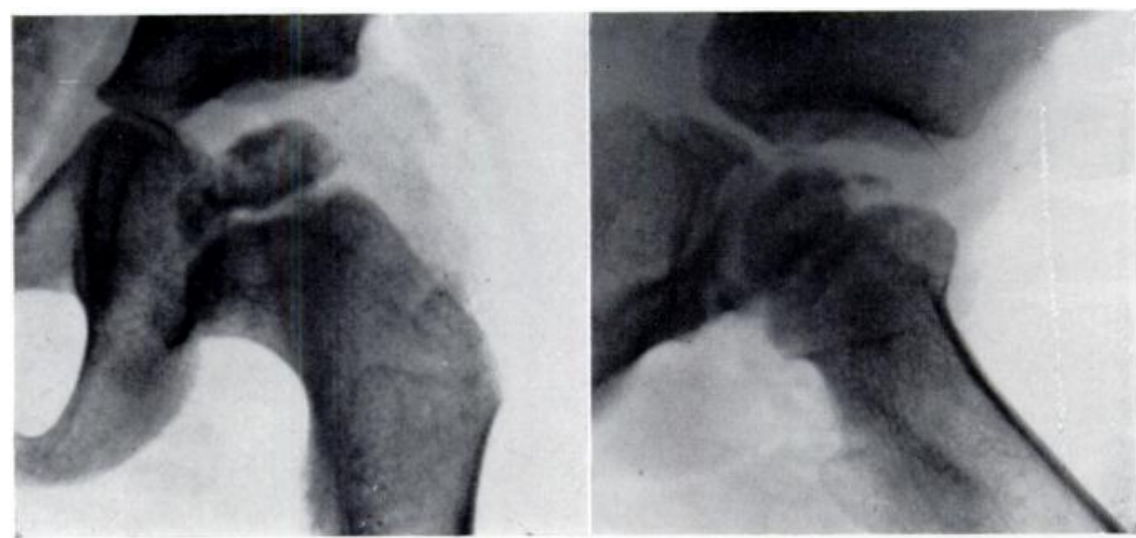

FIG. 10
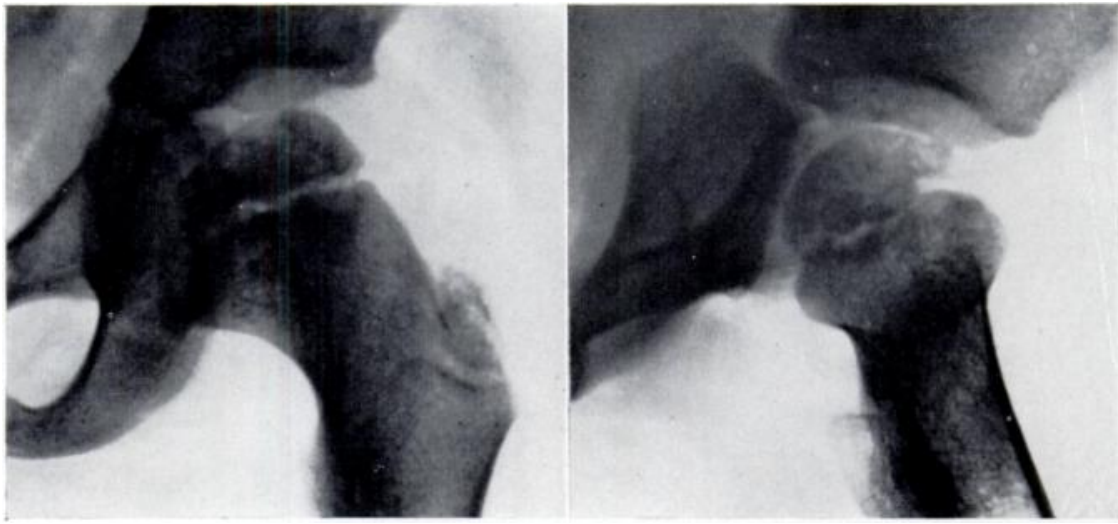

Fig. 11

Case 11. Figure 9-At the commencement of treatment. Aged six years. There is rarefaction of the metaphysis mainly in its anterior third, with early necrosis of the epiphysis. Figure 10-Six months later. The metaphysial lesion has healed and the overlying part of the head has become rarefied. Figure 11-One year after commencement of treatment. Reconstruction is well advanced. Most of the anterior segment of the head appears to have been filled in by new bone.

THE JOURNAL OF BONE AND JOINT SURGERY 
repaired so completely and so rapidly that it seems probable that it might have recovered without treatment. Obviously a more extensive change requires longer treatment. There is no point in having repeated radiographs, and they may in fact be harmful. One examination about four months after the beginning of treatment, the second at the tenth month, and the third at the sixteenth is about sufficient.

It would be gratifying if the pattern of necrosis threw some light on the etiology. Many theories have been advanced, including infection of the hip by organisms of attenuated virulence (Platt 1922, Phemister 1921) and latent hypothyroidism (Cavanaugh, Shelton and Sutherland 1936). But the progress of the condition is not like that of an infection, and careful investigation by serum protein-bound iodine did not support the theory of hypothyroidism (Beiler and Love 1956).

Probably avascular necrosis of the femoral head similar to that which occurs after "slipping" of the epiphysis or fracture of the neck (Axhausen 1923) has been the most attractive theory. But it would be difficult to reconcile a vascular explanation with the pattern observed in this series. It would be necessary to suppose that a large part of the epiphysis

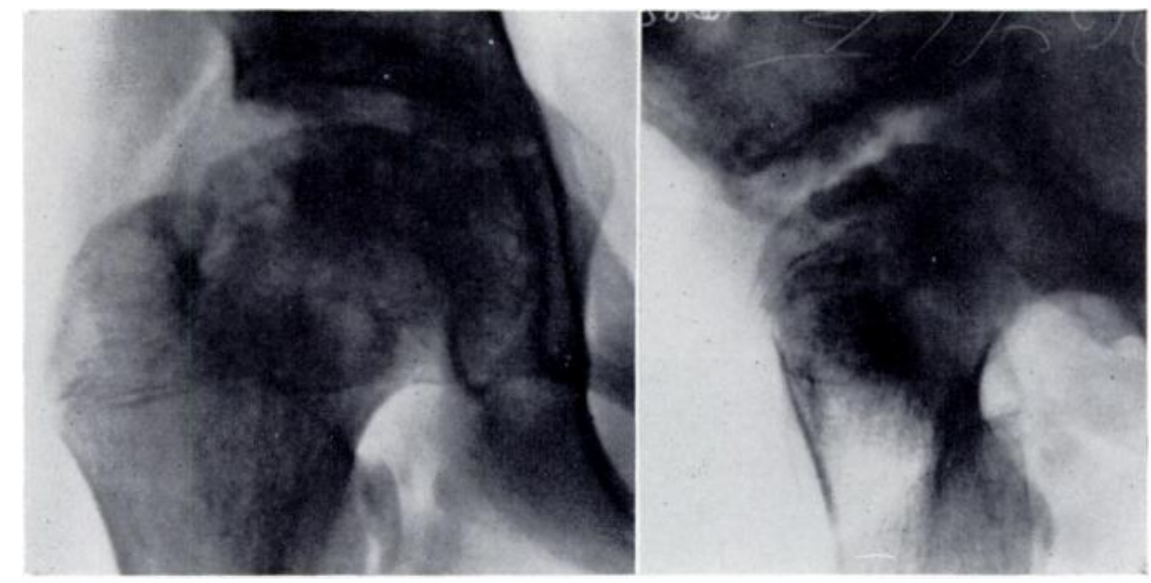

Fig. 12

Case 19. Aged eleven years. After two years' treatment. Situated in the anterior half of the femoral head is a segment of dense bone which is displaced below the level of the normal articular margin. There is very little attempt at reconstruction.

was supplied with blood by a single artery, the blocking of which produced avascular necrosis. Such a supposition is not supported anatomically. Between the age of three years and adolescence the blood supplied to the femoral head travels in the posterior retinacular vessels, which are arranged in superior and inferior groups (Wolcott 1943). The anterior retinacular arteries are small and inconsistent (Tucker 1949) and their blockage could not be expected to cause extensive changes in the head. Trueta (1957) has renamed the posterior retinacular vessels the lateral epiphysial arteries. He stated that these vessels enter the outer segment of the femoral head, slightly posteriorly, and close together, and that the lateral epiphysial arteries are the only source of blood to the head between the ages of four years and eight or nine years, after which the arteries of the ligamentum teres make some contribution to the supply of the head. But one may assume that circulation in the cancellous bone of the head is as free as in other cancellous bone: in other words, once blood has reached one part of the head it can reach all parts. It is of interest that Burrows (1941) was unable to accept arterial block as a cause of Perthes' disease. He concluded that: 1) coxa plana proves histologically to be a condition of necrosis of bone followed by repair ; 2 ) the necrosis differs from ordinary aseptic

vol. $41 \mathrm{~B}$, No. 3, AUGUST 1959 


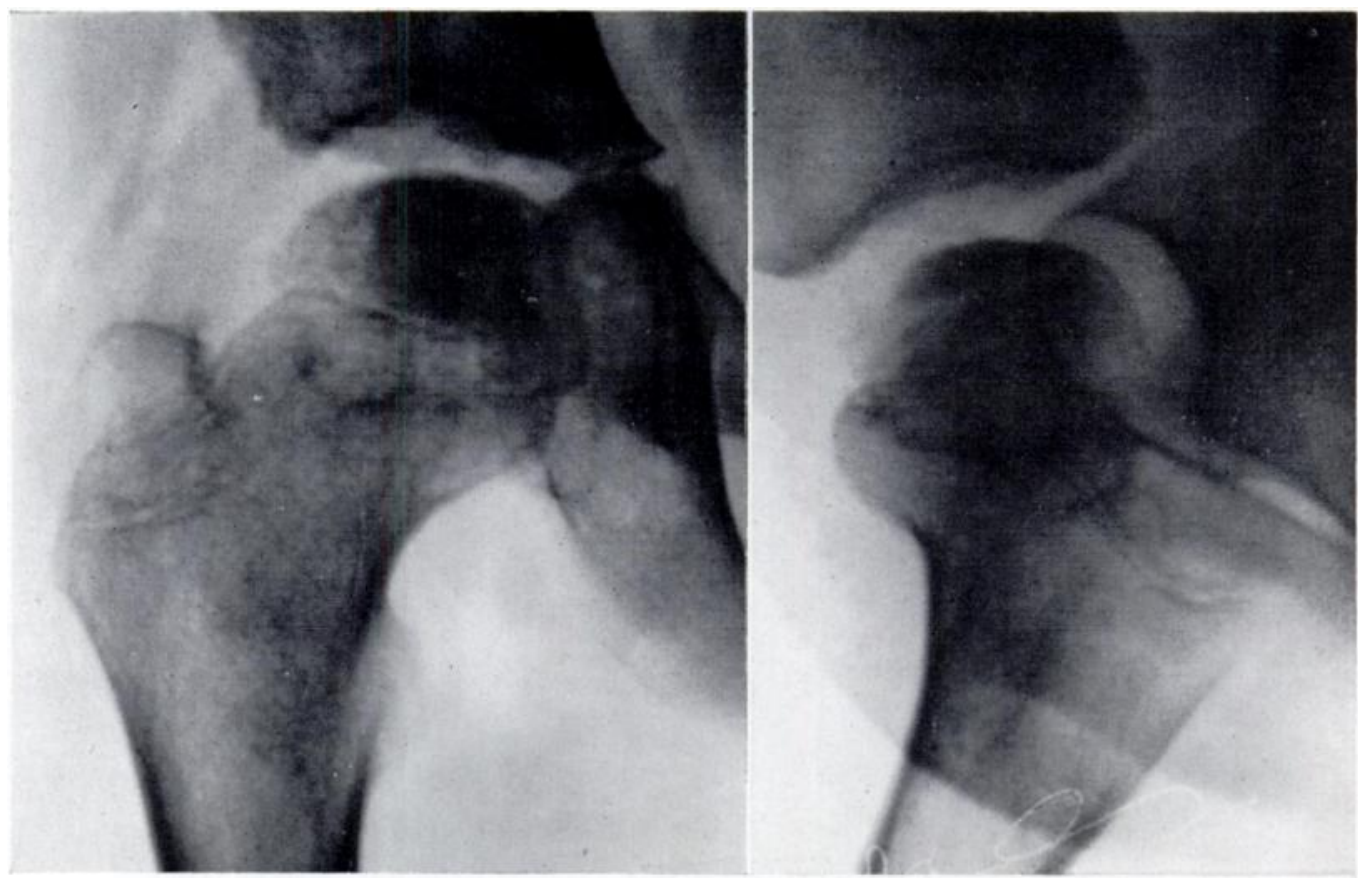

Fig. 13
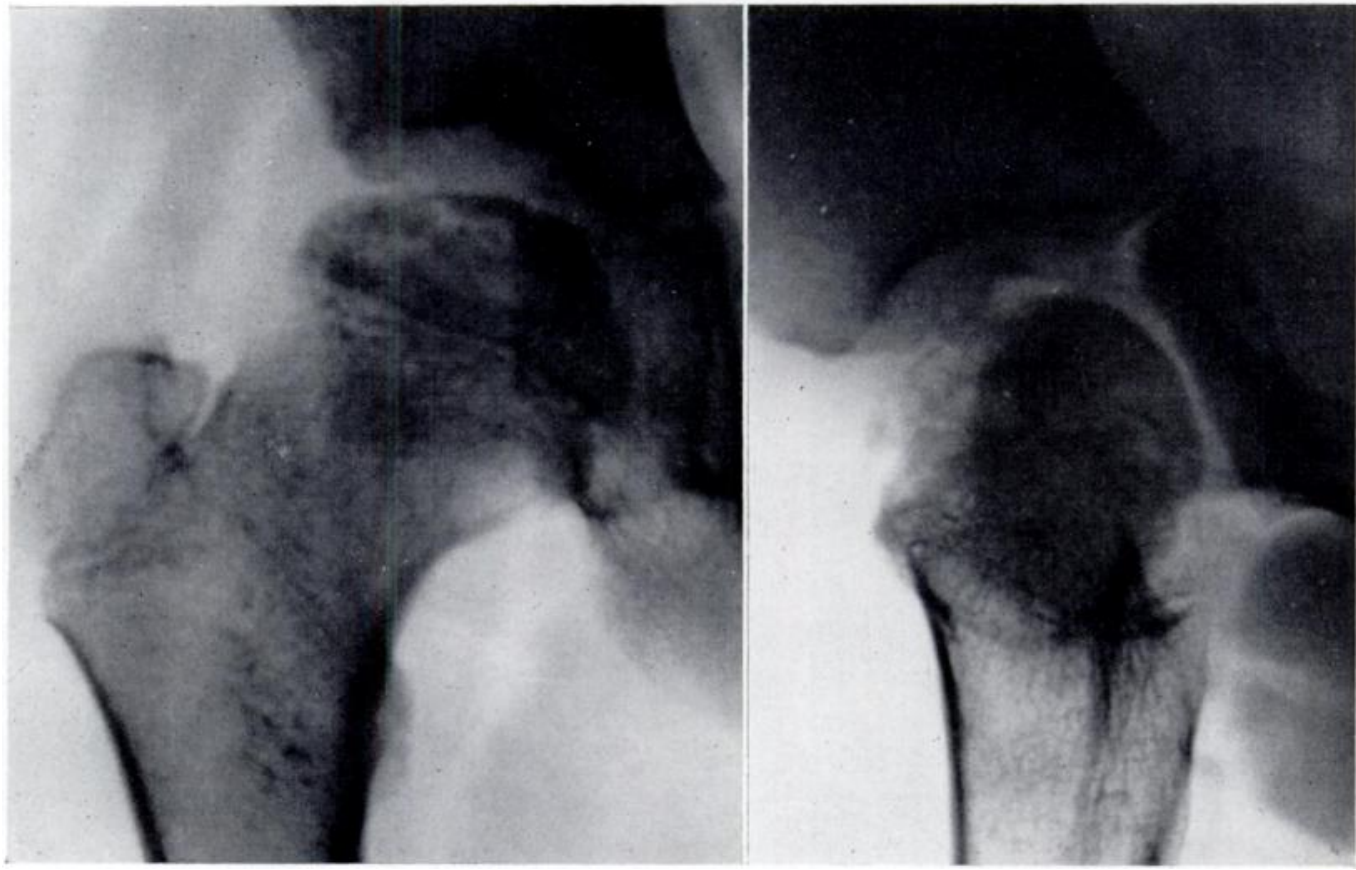

Fig. 14

Case 18-Aged seven years at commencement of treatment. Figure 13-The anterior half of the femoral head is abnormally dense but shows a linear rarefaction. Figure $14-$ Six months later. The dense bone has been removed almost completely from the front of the head. 


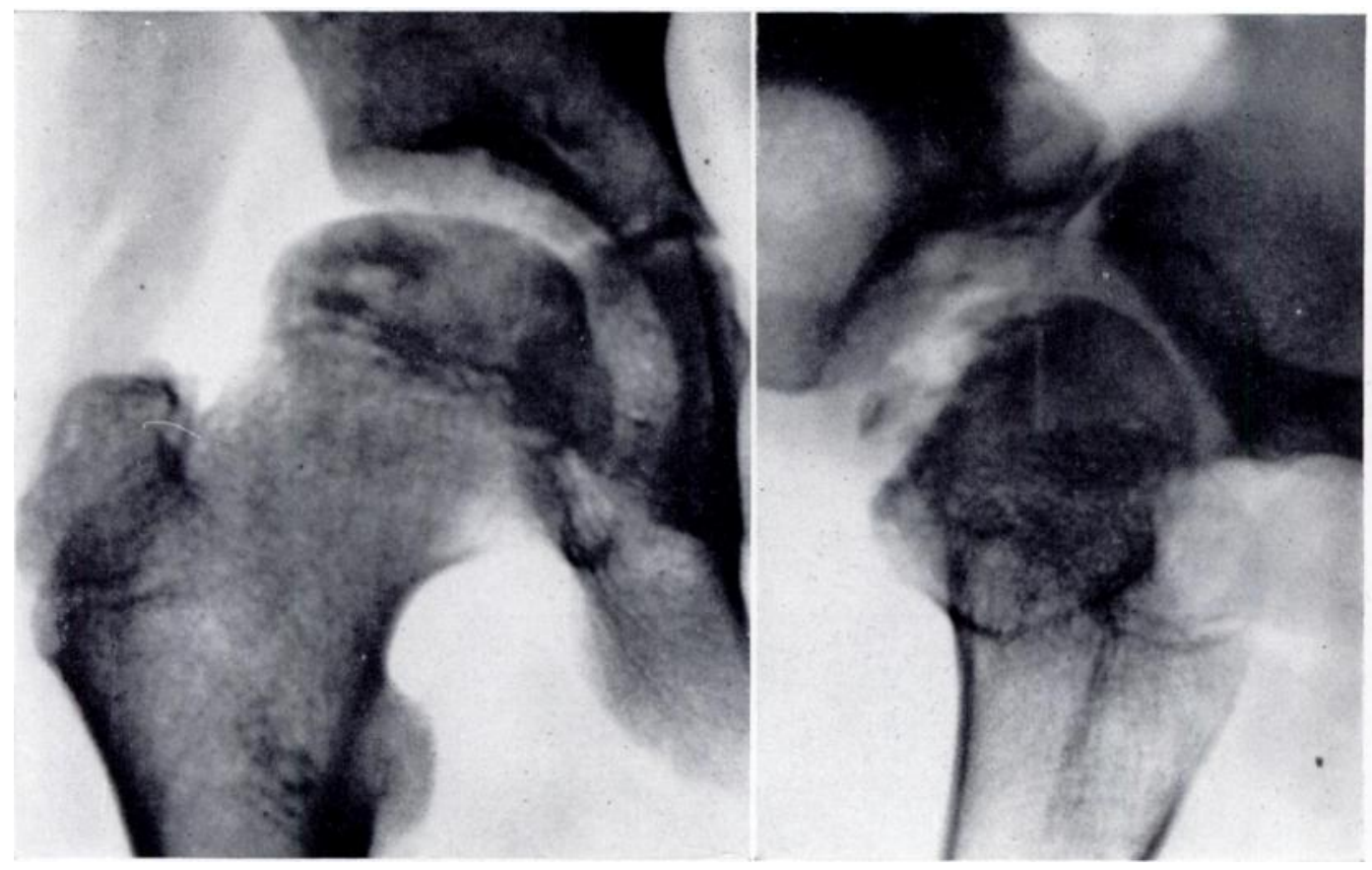

Fig. 15

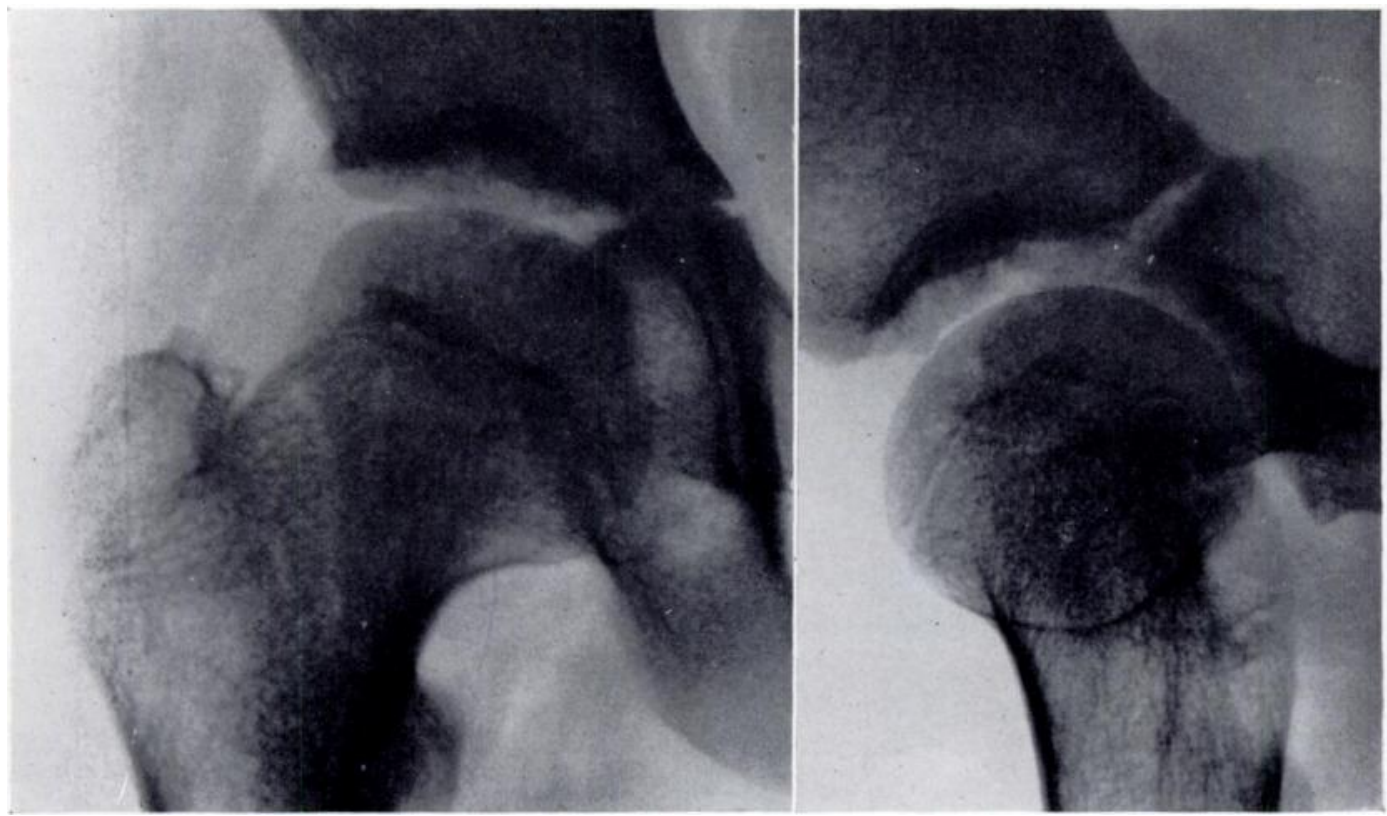

FIG. 16

Case 18. Figure 15-Nine months after commencement of treatment. Reconstruction is beginning in the periphery of the head. Figure 16-Two years after commencement of treatment. Reconstruction is complete after two and a half years. Epiphysial index $=\mathbf{4 0}$.

Vol. 41 B, NO. 3, AUGUST 1959 


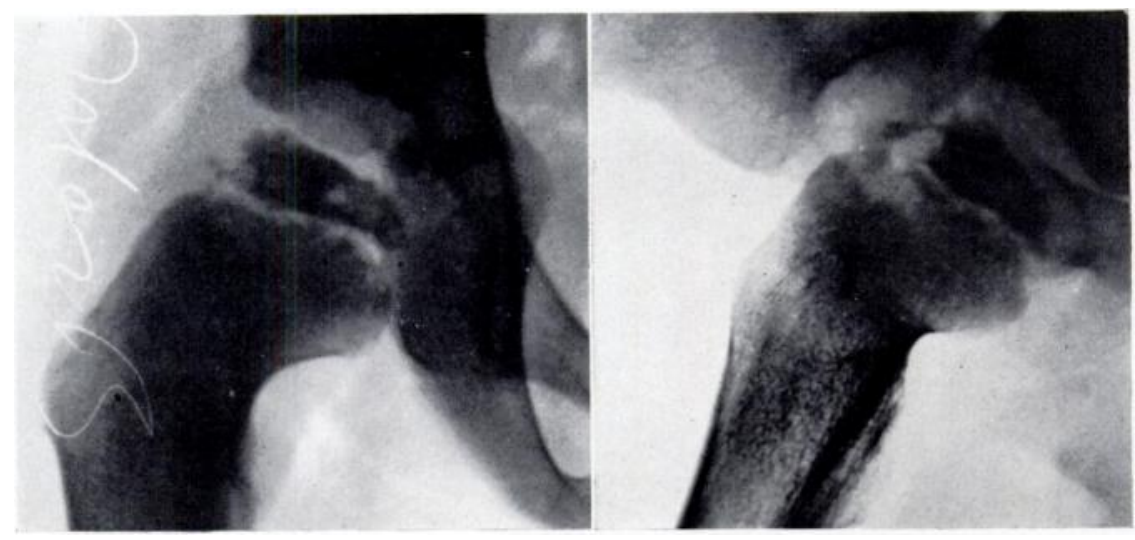

FIG. 17

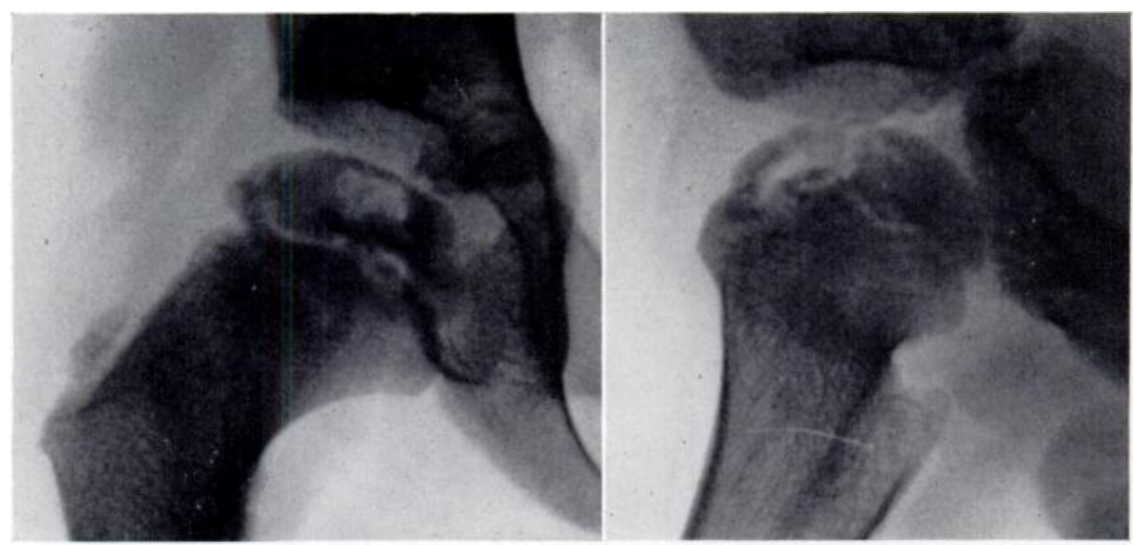

FIG. 18

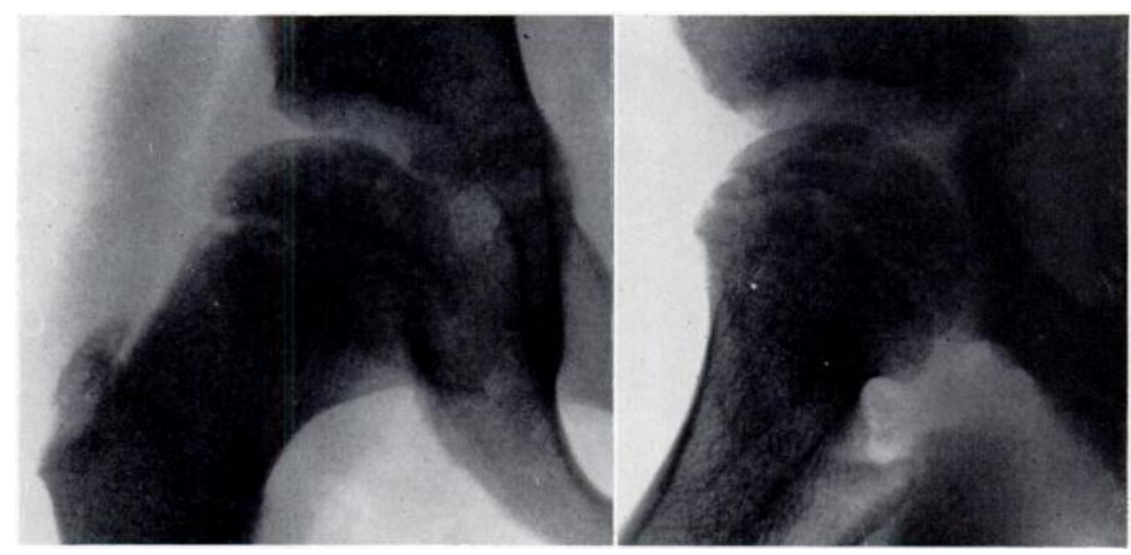

FIG. 19

Case 3-Aged five years at diagnosis. Figure 17-Flattening of the head of the femur is marked. The anterior part of the head is rarefied. Figure 18-One year later. The head of the femur has increased in depth. Reconstruction of the anterior segment is proceeding both at the articular margin and from behind forwards. Figure 19-After three years. Reconstruction is complete. Epiphysial index $=36$. 

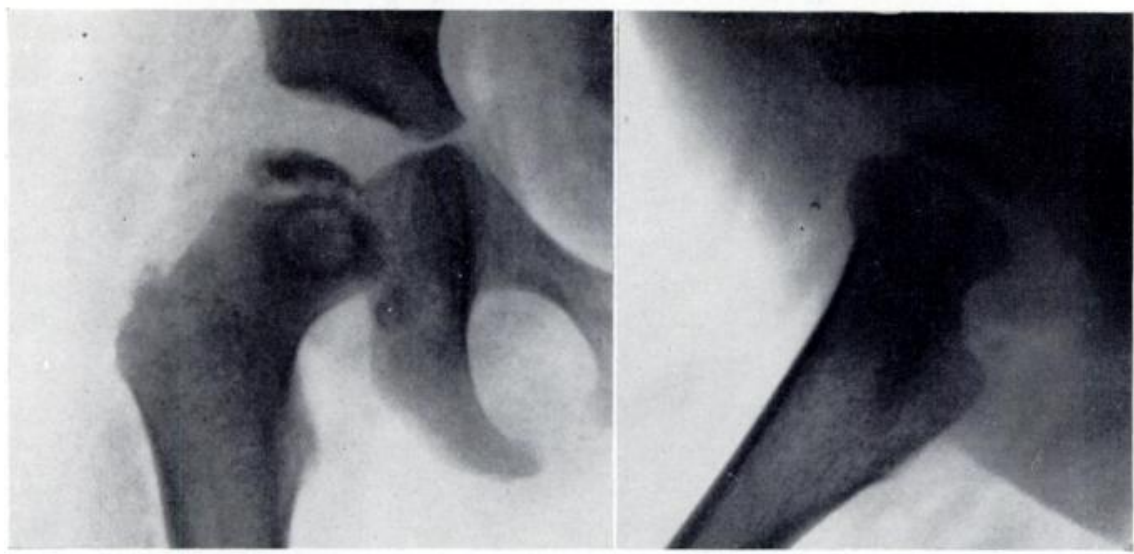

FIG. 20

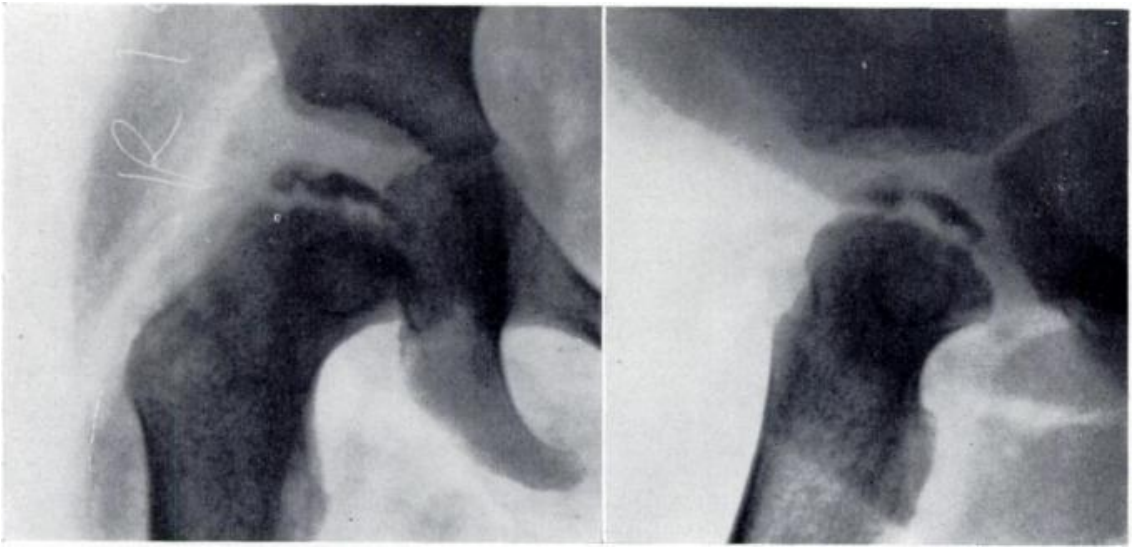

FiG. 21

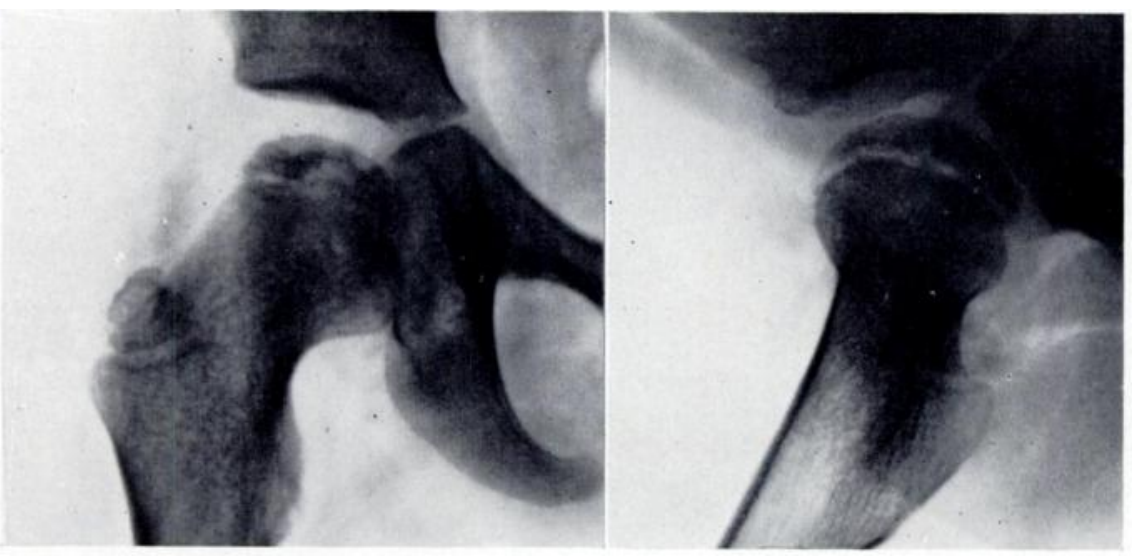

FIG. 22

Case 21-Aged two and a half years at commencement of treatment. Figure 20-The entire head of the femur appears to be flattened and dense. A metaphysial lesion can be seen in the centre of the neck. Figure 21-Three months later. Fragmentation of the whole head of the femur is advanced. Figure 22-A year and a quarter after commencement of treatment. The head of the femur is being reconstructed and is increasing in depth.

VOL. 41 B, NO. 3, AUGUST 1959 
necrosis in showing lysis of trabeculae; 3 ) infection cannot be excluded as a cause of the lysis, but is very improbable; and 4) a possible cause is either venous obstruction or haematoma.

There might well be a similarity between the pathogenesis of Perthes' disease of the hip and that of Freiberg's (or Panner's) disease of the second metatarsal bone. Both show the same basic histological changes (Axhausen 1923): both affect an epiphysis in a segmental pattern, and both tend to heal spontaneously and leave the epiphysis deformed (as if a young mushroom had become middle-aged). Smillie (1957) considered that Freiberg's disease is a form of osteochondritis dissecans. In the present series the radiographic appearance in the femoral heads of the older patients bore a resemblance to osteochondritis dissecans, but both Perthes' disease and osteochondritis dissecans of the hip have been reported in the same patients (Fairbank 1933, Ratliff 1956). Separation of the affected part to form a loose body does not apparently occur in either condition. This is probably accounted for anatomically (Guilleminet and Barbier 1957). No doubt as our opportunities for observation increase so will our understanding, and ultimately it may be found that Perthes' disease, Freiberg's disease and osteochondritis dissecans all have a common etiological factor, operating at differing ages and so with differing effects.

\section{SUMMARY}

1. The progressive radiographic changes in twenty-five patients suffering from Perthes' disease of the hip are described.

2. The prognostic value of lateral views of the hip is emphasised, and the present concepts of pathogenesis in the light of recent observations are discussed.

My thanks are due to Professor Bryan McFarland for much help in the preparation of this paper; also to Mr G. E. Thomas, Mr G. V. Osborne, Miss Norah Walker and many others.

\section{REFERENCES}

Axhausen, G. (1923): Der Krankheitsvorgang bei der Köhler'schen Krankheit der Metatarsalköpfchen und bei der Perthes'schen Krankheit des Hüftkopfes. Zentralblatt für Chirurgie, 50, 553.

Beiler, D. D., and Love, W. H. (1956): Thyroid Function in Legg-Perthes Disease. Journal of Bone and Joint Surgery, 38-A, 1,320.

Burrows, H. J. (1941): Coxa Plana with Special Reference to its Pathology and Kinship. British Journal of Surgery, 29, 23.

Cavanaugh, L A., Shelton, E. K., and Sutherland, R. (1936): Metabolic Studies in Osteochondritis of the Capital Femoral Epiphysis. Journal of Bone and Joint Surgery, 18, 957.

Eyre-Brook, A. L. (1936): Osteochondritis Deformans Coxae Juvenilis or Perthes' Disease: The Results of Treatment by Traction in Recumbency. British Journal of Surgery, 24, 166.

Fairbank, H. A. T. (1933): Osteo-chondritis Dissecans. British Journal of Surgery, 21, 67.

FÈvre, M. (1955): Osteochondritis of the Hip. Clinical Review. Journal of Bone and Joint Surgery, 37-B, 513.

Guilleminet, M., and Barbier, J. M. (1957): Osteochondritis Dissecans of the Hip. Journal of Bone and Joint Surgery, 39-B, 268.

LegG, A. T. (1927): The End Results of Coxa Plana. Journal of Bone and Joint Surgery, 9, 26.

Phemister, D. B. (1921): Operation for Epiphysitis of the Head of the Femur (Perthes' Disease). Findings and Result. Archives of Surgery, 2, 221.

Platt, H. (1922): Pseudo-Coxalgia. British Journal of Surgery, 9, 366.

Ratliff, A. H. C. (1956): Pseudocoxalgia. Journal of Bone and Joint Surgery, 38-B, 498.

Smillie, I. S. (1957): Freiberg's Infraction (Köhler's Second Disease). Journal of Bone and Joint Surgery, 39-B, 580.

TRUeTA, J. (1957): The Normal Vascular Anatomy of the Human Femoral Head during Growth. Journal of Bone and Joint Surgery, 39-B, 358.

TUCKer, F. R. (1949): Arterial Supply to the Femoral Head and Its Clinical Importance. Journal of Bone and Joint Surgery, 31-B, 82.

Wolcort, W. E. (1943): The Evolution of the Circulation in the Developing Femoral Head and Neck. Surgery, Gynecology and Obstetrics, 77, 61. 